\title{
A Decade-or-More's Progress in Understanding Stereotypic Behaviour
}

\author{
J. RUSHEN ${ }^{1}$ AND G. MASON ${ }^{2}$ \\ ${ }^{1}$ Pacific Agri-Food Research Centre, Agriculture and Agri-Food Canada; \\ and the Animal Welfare Program, University of British Columbia, \\ PO 1000, 6947 Highway 7, Agassiz, BC, VOM 1A0, Canada; \\ ${ }^{2}$ Department of Animal and Poultry Sciences, University of Guelph, \\ Guelph, Ontario, N1G 2W1, Canada
}

\section{Editorial Introduction}

To open the book, we review the extent and nature of research into stereotypic behaviour since the first edition was published 13 years ago. We compare the numbers of recent papers on captive animals with those on human clinical subjects or research animals experimentally manipulated to produce abnormal behaviour, and also show some recent meta-analyses of trends within the former group. Contributed boxes present simple overviews of the motivational explanations typically used by ethologists, versus explanations in terms of brain function, and also review how the terms 'coping' and 'pathology' have been used. We then assess the extent to which the research questions raised by the last volume have been answered, and end by introducing this new edition's website and how the following chapters are organized.

GM and JR

\subsection{Introduction}

In this chapter, we review the scope and layout of the book and its accompanying website, and introduce some key concepts that recur throughout the volume, such as 'coping' and 'pathology'. We also discuss the extent to which this volume addresses the research questions highlighted at the end of the first edition (Lawrence and Rushen, 1993). This was published more than a decade ago, and set out to review what was then known about stereotypic behaviour with particular attention to the implications for animal welfare. Why is a second edition warranted? Presumably there has simply been enough new material on stereotypic 
behaviour of animals to convince the publishers, editors and contributors that a new edition was justified. But to what extent have the issues raised in the earlier edition been successfully resolved? What new issues have emerged? And how does this new edition resemble or differ from the old?

\subsection{Research on Stereotypies since the First Edition}

In the introduction to the first edition, Lawrence and Rushen (1993) reported that a total of 63 papers had been published on the stereotypic behaviour of farm animals over the preceding 27 years. Of these, nearly a third were reviews, while the majority of data-based studies were mainly descriptive, with few studies experimentally manipulating likely causal factors. Lawrence and Rushen (1993) posited an unsurprising list of potential reasons for the low volume of articles at that time. These included a lack of interest, a lack of money, a tendency to 'talk rather than do', as well as some more subtle issues such as seeing animal stereotypic behaviour as a problem to be solved rather than a phenomenon to be understood.

The second and last issues probably remain with us, but there is no doubt that scientific interest in the underlying causes of these behaviours has increased substantially. In fact, a recent search of the ISI Web of Knowledge (http://isiwebofknowledge.com/) reveals that since the last edition, an average of 16 papers a year have been published on captive animals' stereotypies - a total of 188 from the start of 1993 to the end of 2004 (see Fig. 1.1). This number is dwarfed by research on the stereotypies of human clinical subjects and of laboratory animals subjected to genetic modification, brain lesion or psychopharmacological challenge (yielding around 120 papers a year - see Fig. 1.1). However, it nevertheless represents a substantial increase in rate, and a substantial volume of new research to assimilate.

Three things are striking about the articles now being published on captive animals' stereotypies. The first is that a growing number - as we will see in this volume (especially Chapters 5-8) - now draw explicitly from those other main sources of research into stereotypic behaviour: neuroscience, clinical psychology and psychiatry. The second is that since the first edition, there is a far greater concentration on trying to understand why animals perform these rather bizarre-looking behaviours, i.e. more investigations that unravel the causal factors rather than simply describe what the animals are doing. Although there remains the very practical desire to prevent these behaviours from occurring wherever possible (see e.g. Chapters 9 and 10, this volume), it is thus clear that researchers have recognized the need to base such 'prevention or elimination' strategies upon a greater understanding of why such behaviours occur. Furthermore, there is also a growing realization that such behaviours have much to tell us about how 'normal' behaviour 


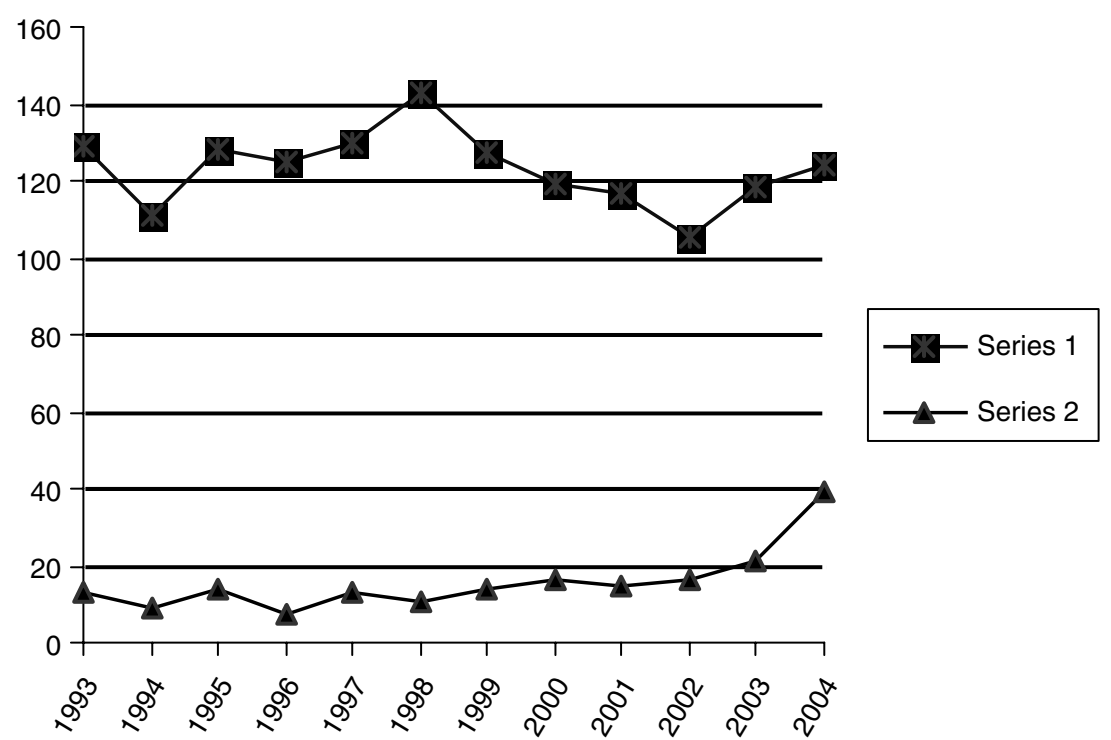

Fig. 1.1. The number of refereed publications on stereotypy, annually over the last 12 years. Records are divided into: Series 1 - papers on human patients, plus lesioned, pharmacologically treated or otherwise manipulated laboratory animals; Series 2 - papers on stereotypies emerging 'spontaneously' in captive animals.

is organized and controlled, and even about the likely psychological or neurophysiological normality of many of the millions of animals kept by humans worldwide.

The third change in the last decade or so is that a diverse array of animal species is now being studied. In 1993, most work on stereotypic behaviour focused on farm animals, or on drug-induced stereotypies in laboratory rodents. Although zoo biologists had carried out pioneering work describing these behaviours, and had raised attention (and some alarm) as to what they may mean for welfare, there were few systematic attempts either to understand or to prevent the occurrence of such behaviours in zoos. In the last 12-13 years, however, a great increase in interest in zoo animals is very evident (see e.g. Chapters 3 and 9, this volume). This has been paralleled by more research on 'spontaneous' cage stereotypies in laboratory animals (Chapters 4, 5, 7 and 8, this volume), and a growing interest in the 'problem behaviours' - including stereotypies - of the cats, dogs and horses that we keep as companion animals (Chapters 2 and 10, this volume). Indeed one reason that we added a website to this new edition (see http://www.aps.uoguelph.ca/ gmason/StereotypicAnimal Behaviour/) was to illustrate this new diversity with images and video-clips.

One result of the increased volume and taxonomic diversity of research into cage stereotypies is that it has recently allowed meta- 
analyses, in which the data contained in existing papers and reports are pooled for further statistical analysis to look for overall patterns or even test specific hypotheses. Such analyses are useful in revealing broad trends that would not be evident in single studies involving a small number of individuals of a single species, and can even test hypotheses that would be challenging to investigate otherwise. Two nice recent examples are presented in Chapters 3 and 9, this volume. We also give three other instances here, to further help set the scene for this new edition. First, Mason and Latham (2004) were able to estimate the total number of stereotyping animals worldwide. Although approximate, it does illustrate the vast scale of this phenomenon (see Table 1.1). The same authors also investigated the relationships between stereotypic behaviour and other measures of poor welfare. The authors pooled several hundred papers, and sorted them by the control group used as a comparison. In one type of study, animals performing stereotypic behaviour were compared with low- or non-stereotyping animals that had been raised or kept in different conditions. In the other type of study, the low- and highstereotyping animals under comparison came from the same treatment conditions, but showed spontaneous individual differences in the behaviour. The particular treatments that led to a high incidence of stereotypic behaviour were, as we have long suspected, often linked with other signs

Table 1.1. Estimated total numbers of stereotypers for some major species/production groups (modified from Mason and Latham, 2004). Totals here represent those occurring over a period of approximately 6 months; true annual figures would be larger because of those animals generally kept for less than 12 months (e.g. laboratory mice).

\begin{tabular}{lccl}
\hline $\begin{array}{c}\text { Species } \\
\text { (system) }\end{array}$ & $\begin{array}{c}\text { Estimated } \\
\text { stereotypy } \\
\text { prevalence } \\
\text { (\% individuals) }\end{array}$ & $\begin{array}{c}\text { Estimated } \\
\text { number of } \\
\text { stereotypers }\end{array}$ & $\begin{array}{c}\text { Notes (see Mason and Latham, 2004 } \\
\text { for details of all data sources) }\end{array}$ \\
\hline $\begin{array}{c}\text { Pigs } \\
\text { (confined sows) }\end{array}$ & 91.5 & $15,393,000$ & $\begin{array}{c}\text { Estimated for Europe and North } \\
\text { and Central America only }\end{array}$ \\
$\begin{array}{c}\text { Poultry (broiler } \\
\text { breeders) }\end{array}$ & 82.6 & $56,498,000$ & $\begin{array}{c}\text { Estimated for Europe and } \\
\text { North America only }\end{array}$ \\
$\begin{array}{c}\text { Mice (research } \\
\text { and breeding } \\
\text { establishments) }\end{array}$ & 50.0 & $7,500,000$ & $\begin{array}{c}\text { Stereotypy prevalence is a conservative } \\
\text { guessed estimate; prevalence data } \\
\text { are published only for a very high } \\
\text { stereotypy strain where almost all } \\
\text { individuals are affected; more data on } \\
\text { common strains are therefore needed } \\
\text { Prevalence estimate here ideally needs } \\
\text { data from more farms } \\
\text { ( } N=2 \text { in this estimate) }\end{array}$ \\
$\begin{array}{c}\text { American mink } \\
\text { (breeding females } \\
\text { on fur farms) }\end{array}$ & 80.0 & $4,680,000$ & $\begin{array}{c}\text { Population size is for the } \\
\text { 'developed world' }\end{array}$ \\
Horses (stables) & 18.4 & $2,724,000$ & \\
\hline
\end{tabular}



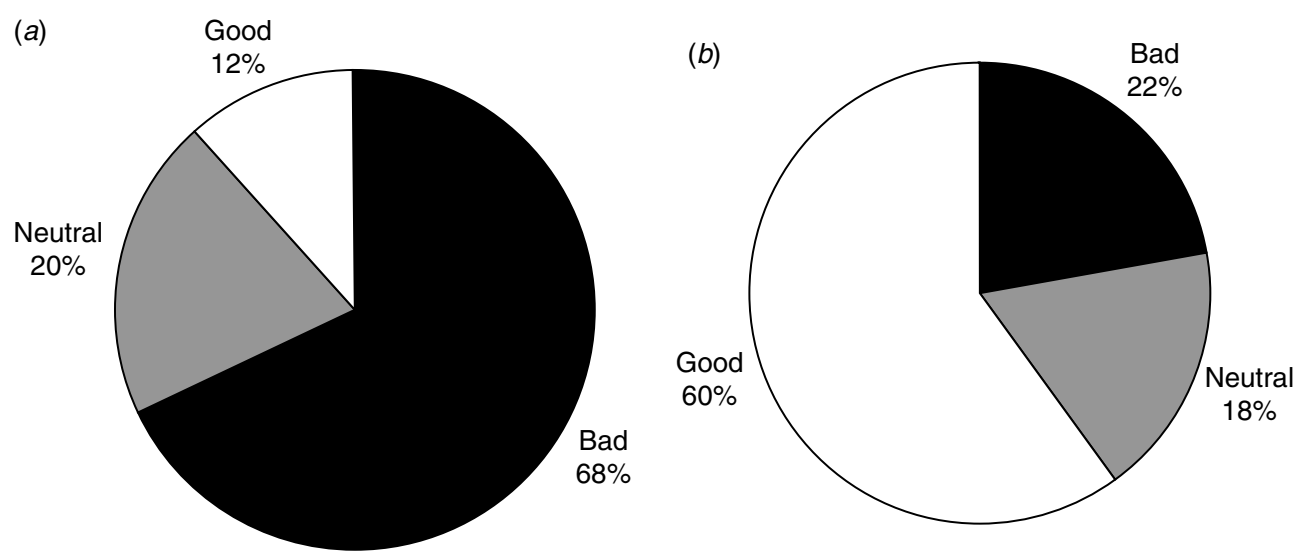

Fig. 1.2. How stereotypies and other welfare measures covary (modified from Mason and Latham, 2004). Accounts reporting additional welfare measures along with stereotypy (e.g. heartrate changes, approach/avoidance behaviour, corticosteroid outputs) were scored as to whether they linked high stereotypy with decreased ('bad'), unchanged ('neutral') or improved ('good') welfare relative to no-/low-stereotypy controls. (a) Shows results from 196 reports where stereotypers and low-/non-stereotyping controls came from different treatment groups (e.g. different housing conditions or feeding regimens). (b) Shows results from 90 reports where stereotypers and low-/non-stereotyping controls came from within the same population/treatment group. The resulting patterns are significantly different from chance, and also significantly different from each other; see Mason and Latham (2004) for more details.

of poor welfare (see Fig. 1.2a). However, high stereotypy individuals within such environments often seemed 'better off' rather than 'worse off' than low-stereotyping animals (see Fig. 1.2b). This overview shows that the environmental factors that elicit stereotypies are not the same as the individual characteristics that predispose individual animals to develop the behaviours, an issue that recurs throughout this book. The third meta-analysis, also by Mason and colleagues, broke down abnormal behaviours (including stereotypy) by taxon, to show that different orders of mammals typically favour different types (see Fig. 1.3), and highlighting the value of research across a wide range of species.

\subsubsection{Clarifying terminologies}

One issue of note, as we survey these diverse pieces of work, is that researchers from different fields have, unsurprisingly, different interests, terminologies, assumptions and modes of explanation. Therefore, in an effort to help non-ethologists appreciate motivational explanations of animal behaviour (including stereotypies), both within these primary publications and in the chapters that follow, we present a box at the end of this chapter that gives a basic introduction (see Box 1.1). To follow this, and to likewise help ethologists appreciate how the vertebrate 


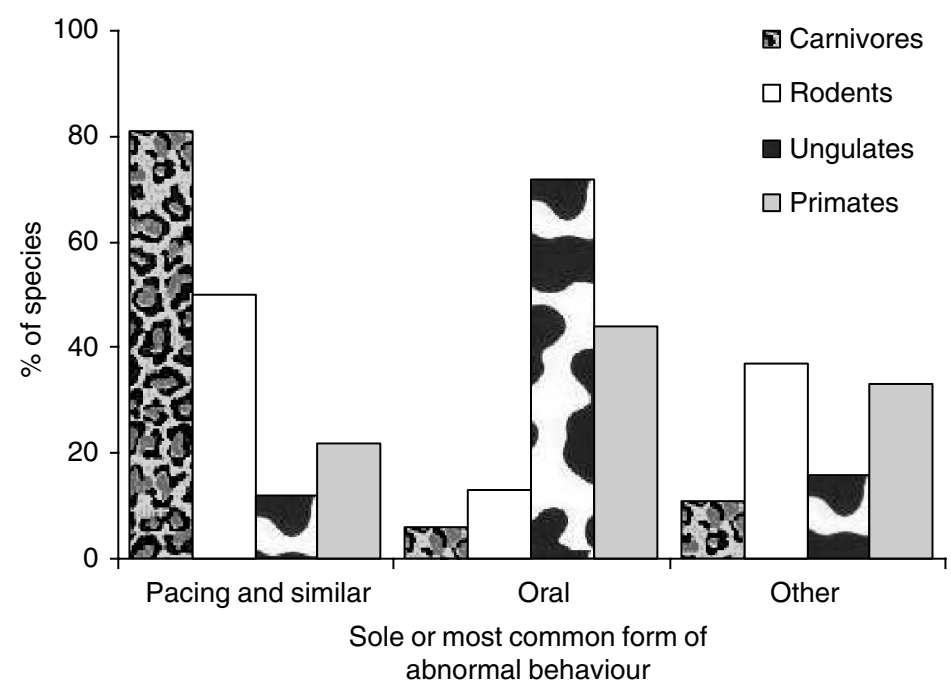

Fig. 1.3. The taxonomic distribution of different forms of abnormal behaviour (from Mason et al., in press). For this survey, abnormal behaviours were defined as not known to occur in the wild, with no obvious goal or function; they thus included stereotypies, but also other behaviours, e.g. overgrooming; regurgitation-and-reingestion. Animals with apparent severe CNS dysfunction (e.g. experimentally treated with psychoactive substances, or performing self-injurious behaviours) were excluded; and husbandry differences between taxa were controlled for as much as possible (see Mason et al., 2006, for details). Abnormal behaviours were categorized as: (i) pacing and similar (i.e. locomotory movements); (ii) oral (e.g. sham-chewing); and (iii) other (e.g. non-locomotory body movements like body-rocking or repetitive jumping). The 61 carnivore, 26 ungulate, 15 rodent and 19 primate species for which reports were obtained were each classified according to their sole or most commonly reported form. The frequency of different typical forms varied significantly with taxon $\left(\chi^{2}=51.17 \mathrm{df}=6 P<0.001\right)$.

brain generates behaviour (including abnormal behaviour), we give a very simple introduction in Box 1.2.

Furthermore, some terminology is used across multiple disciplines, but has connotations that are either rather vague or that vary between fields. Two such terms particularly relevant to discussions of stereotypy are the concepts of 'coping' and of 'pathology'. Boxes 1.3 and 1.4 therefore review these, to provide a reference definition or level of understanding that many other authors will then refer to in the chapters that follow. Again, these are given at the end of this chapter.

\subsection{Issues Resolved since the Last Edition?}

At the end of the last edition, Ödberg (1993) summed up some of the main issues concerning stereotypic behaviours that were then taxing the minds of investigators. He also made research recommendations for the future, 
as follows (his italics): '(1) Carry out as far as possible developmental studies, trying to induce stereotypies and investigating what changes in the organism; (2) Study individual differences (high/low, stereotypers/ non-stereotypers, between stereotypers, between non-stereotypers), investigating in which aspects they differ other than in performances of stereotyping; (3) Use increasingly interdisciplinary approaches, especially neuropsychological and biochemical ones, with more attention on cognitive processes; (4) Keep an open mind for different hypotheses' (p. 187). Has his advice been followed? We would have to answer with a resounding 'yes'. For example, Chapter 8 is one nice example of the first recommendation, Chapter 7 of the second, and Chapter 5 of the third; and all the chapters in the book show a desire to put forward and evaluate alternative hypotheses.

Of course, far more could be done, however, and both the overviews above and the chapters that follow reveal a number of omissions or 'blind spots'. First, much relevant literature is still not adequately used or referred to by those seeking to explain stereotypies. For example, the literature search behind Fig. 1.1 threw up a lot of hits (not included in the figure) about naturally stereotyped responding in simple neural systems (e.g. some insect movement patterns), or in what used to be termed 'fixed action patterns' such as some bird songs. These types of phenomena were discussed in the first edition (e.g. Mason, 1993) yet seem to have been forgotten in the last decade, an issue Mason returns to in Chapter 11. Second, the flow of ideas from neuroscience to ethology and related disciplines seems so far to have been one way. Third, research on avian stereotypies, even those of poultry, seems to have all but disappeared. Fourth, researchers using different types of animals have tended to also use different research approaches and techniques; this means that we quite simply do not yet have a complete understanding of the motivational, developmental and neurophysiological underpinnings of any single model. Chapter 11 takes this last issue further, but first, let us flag the main issues that were taxing researchers 12-13 years ago, and see to what extent they have been dealt with here.

\subsubsection{What is a stereotypy?}

The question of how to define or classify stereotypies was an important issue (Mason, 1993), not only because it was evident that different investigators were using different methods to decide which behaviours were included as stereotypies, but also because many of the disputes about the causes and functions of stereotypies arose partly because of a mistaken assumption that the class of stereotypies was homogeneous. Difficulties in interdisciplinary communication about stereotypies were thus thought partly to result from the fact that stereotypy meant different things in different disciplines (Ödberg, 1993). Could we assume that the same causal factors were responsible for stereotypic rocking in maternally deprived 
primates, stereotypic pacing in caged lions and stereotypic bar-biting by tethered sows? Should other behaviours, e.g. polydipsia in schedule-fed rodents or non-nutritive sucking by milk-fed calves, be included as stereotypies? Did the occurrence of all forms of stereotypic behaviour have the same implications for welfare across these very different animals?

The decision to classify any given behavioural pattern as a stereotypy depended, primarily, upon the way that the behaviour was performed, i.e. whether in a repetitive and invariant manner. Here, the question focused upon how much the performance of a behaviour actually had to be repetitive and invariant for it to count: detailed studies of stereotypies revealed that there was quite a deal of variability both in the timing of the performance and its repetitiveness. Clarity of the description of each instance of stereotypic behaviour is essential in comparing different studies. However, many 'normal' behaviours are also performed in a stereotypic manner, yet go unremarked. What was striking about the stereotypies being studied was that they appeared to have no function, which implied a certain degree of abnormality (however vaguely defined). It was this quality that focused the minds of researchers interested in animal welfare upon the possibility of using them to assess welfare, and to some extent a suggestion of 'abnormality' was often implicit in the decision as to whether or not any given behaviour would be included in the category of 'stereotypy'.

So, to what extent have we made progress in the way that we describe, measure and classify such behaviours? As we will see, the issue of classification and definition remains a very live one today, indeed one rendered even more important by the growing use of psychopharmacological treatments that might simply be inappropriate if we mistake the true aetiology of a particular behaviour (Chapter 10, this volume). Thus, calls for classificatory schemes are made in Chapters 2 and 4, and responses, in the form of suggested frameworks, are proposed in Chapters 5, 10 and 11. Some of the diverse behaviours that may or may not be included in future schemes are portrayed on this book's website, again to help illustrate the diverse properties of the behaviours discussed by different authors; see http:// www.aps.uoguelph.ca/ gmason/StereotypicAnimalBehaviour/.

\subsubsection{What causes stereotypies?}

Lawrence and Rushen (1993) complained of the relative lack of systematic research to understand the causal bases of these behaviours. According to Ödberg (1993), what causal analyses had been undertaken consisted of a list of factors that might affect the occurrence of such behaviours rather than any theoretical framework based on an understanding of the organization of behaviour.

Understanding the basic causes of the behaviours is important, not only to advance fundamental scientific knowledge of how behaviour is organized, but also because the appropriate use of stereotypic behaviours to assess animal welfare requires that we understand why animals per- 
form them. Further, it would seem likely that attempts to prevent stereotypies from occurring would benefit from a greater understanding of their causes. In the first edition of this book, the causal basis of stereotypies was approached from an analysis of the motivational (see Box 1.1), the neurophysiological and the emotional underpinning, but most approaches were essentially behavioural. A genuine theoretical model of the causes of stereotypies, however, requires that we pool our insights and adopt a more interdisciplinary approach, uniting neurophysiological, motivational and cognitive approaches (Ödberg, 1993).

To what extent have we done that? Readers must decide this for themselves as they read through the volume, but several chapters in the present volume seem to represent major advances, for instance discussing novel and hypothesis-driven cross-species comparative work on carnivores (Chapter 3, this volume), beautifully designed ethological experiments on rodents (Chapter 4, this volume), new and innovative uses on animals of the psychological tests used on human patients (Chapter 5, this volume) and sophisticated investigations of the behaviour's neurophysiological underpinnings (Chapters 7 and 8 , this volume). Furthermore, one general proposal that has resurfaced in recent years is that stereotypies are pathological (see Boxes 1.2 and 1.4 for background). This term had been used in a rather loose way with respect to stereotypies for decades, but as Chapters 5, 6, 10 and 11 of this edition illustrate, it is now being used with much more precision, with uncomfortable implications for the way we currently house and use animals, and generating hypothesis-led ideas for future research.

\subsubsection{How do stereotypies develop and change over time?}

Ödberg (1993) drew attention to the need for more 'developmental' studies, following the history of such behaviours in individuals. This had been found useful for generating hypotheses about the causal basis of such behaviours (Cronin et al., 1985), and had also shown that with time, stereotypic behaviours could sometimes become emancipated from the underlying causal factors, so that different factors affected stereotypies early in their development than when they had become fully 'established'. This finding potentially has important implications for research that tries to understand the causal basis of the behaviour, and equally for attempts to prevent or suppress stereotypic behaviour (see e.g. Mason and Latham, 2004). But has our understanding progressed? Some developmental effects are focused on in Chapter 6, which discusses the role of early social loss in primates, and Chapter 7, which discusses the role of early physical complexity. These all add substantially to our knowledge of 1993. Chapters 2, 3 and 4 also review the long-standing ideas about how developed stereotypies then change with repetition. However, the real lack of longitudinal studies of stereotypy, i.e. following individuals over time, remains striking - an issue Mason returns to in Chapter 11. 


\subsubsection{What is the welfare significance of stereotypies?}

One question that was inadequately addressed in the first volume is a central question in animal welfare: to what extent does the occurrence of stereotypies reflect emotional suffering? Stereotypies were often assumed to occur when animals were 'stressed', an assumption undismayed by the lack of any clear definition or broadly accepted marker of stress. Since 1993, we have developed far more sophisticated, and diverse, notions of what constitutes stress, and when it is most useful to apply the concept (e.g. Moberg and Mench, 2000; Chapter 8). Has this advanced our understanding of stereotypies as part of the stress response, or as an indicator of poor welfare?

Although discussing cause rather than welfare significance was the remit of our authors, Chapters 2-8 do show how the causal factors of stereotypy are all essentially forms of stress or deprivation, while Chapter 5 presents a fascinating attempt to understand the mental world of animals performing stereotypies, from the view that they reflect some functional brain pathology. Chapter 8 even proposes a new definition of stress, central to which are the types of brain change that stereotypies may derive from. However, several chapters also provide evidence that it would be very naïve to assume simply that 'high stereotypy = bad welfare, no stereotypy = good welfare'. Mason discusses this further in Chapter 11, but let us briefly look at one potential reason for this: 'coping'.

\subsubsection{What is the function of stereotypies?}

Those with pedantic minds might complain of attempts to understand the function of behaviours that are, by definition, functionless. But the description of stereotypies as being apparently functionless was always more of an admission of our ignorance than a genuine description of the behaviour. In the early 1990s, particularly in the domain of farm animal welfare, there was considerable interest in the notion that the performance of stereotypic animals might actually help animals cope with stress (Dantzer and Mittleman, 1993; see also Box 1.3). For example, some of this earlier work had raised the question as to whether the performance of stereotypic behaviour helped reduce 'arousal' in animals. However, it was the finding that the performance of apparently stereotyped behaviours might be associated with a reduced hypothalamo-pituitary-adrenocortical (HPA) axis response to stress that led to the 'coping hypothesis' of stereotypies and which generated considerable research attempts to demonstrate this. By the time of the first edition of this book, however, these attempts had produced somewhat mixed results and only limited support for the coping hypothesis (Dantzer and Mittleman, 1993; Ladewig et al., 1993). Have we progressed? Box 1.3 certainly helps to illustrate how sophisticated ideas have become about this; and recent evidence that some stereotypic behaviour brings with it benefits is presented in Chapters 2 and 6. It is clear, however, that as yet, more questions are 
raised on this topic than are answers, an issue Mason returns to in Chapter 11.

\subsection{The Structure of the Book}

In this book, we have selected authors who present very different perspectives on stereotypic behaviour. Chapters 2-4 (Part I) come from an ethological perspective. They discuss behaviour, including stereotypies, in terms of its motivational bases, and implicitly (or sometimes explicitly) assume that their stereotyping subjects are normal animals responding in species-typical ways (typically maladaptive ones sensu Box 1.4) to abnormal environments. The emphasis here is on the mismatches between the environment an animal has evolved to deal with and that into which it is placed by humans. Thus, species differences are acknowledged as an important source of variation, and even as a source of useful data with which to test hypotheses further. Furthermore, species are typically seen as important in their own right, rather than as 'models' for other organisms or conditions. The work in these chapters helps in particular to explain the form and timing of different stereotypies.

In contrast, Chapters 5-8 (Part II) have closer ties with clinical psychology, psychiatry and neuroscience. These authors typically work on three assumptions that differ from those in Part I: first, that their stereotypies of focus are the product of dysfunction, i.e. the animal is abnormal, not normal; second, that the fullest understanding of them will come from investigating the neurophysiological mechanisms involved and third, that the processes involved at this level have great cross-species generality. Thus, animals are often used as 'models' believed to display at least some of the features of the 'real' subject of interest - in practice often humans with clinical conditions. The studies reviewed here help to explain the extraordinary invariance and/or persistence we see in some forms of stereotypic behaviour.

In Part III, two chapters (Chapters 9 and 10) then illustrate how stereotypies can be tackled and reduced by those concerned about their unaesthetic appearance and/or welfare implications. These efforts are usually post hoc reactions to stereotypies that have emerged and been deemed problematic, typically in zoo and companion animals, whose abnormal behaviours ironically have attracted the least fundamental research. Finally, we end (Chapter 11) with a synthesis, suggestions for future research and suggestions for how terminology could perhaps improve.

Note that all chapters contain 'boxes', sometimes by the chapter's own authors, sometimes by others, that are designed to be delved into or skipped over at will. These have a number of functions. Sometimes they elaborate a self-contained 'sub-topic'; sometimes they add relevant examples, from other areas, to the topic covered in the main text; sometimes they expand on central issues that may not be familiar to all disciplines and last but not least, sometimes they flag topics of disagreement or controversy. 
Box 1.1. Motivation and Motivational Explanations for Stereotypies

\section{R. Clubb, S. Vickery and N. Latham}

Motivational explanations of stereotypies seek to understand how they arise via an animal's internal states and responses to external stimuli. These internal and external factors are considered the same as those underlying the initiation and termination of adaptive, speciestypical behaviour patterns. Motivation is thus an ethological construct used to describe why normal animals do what they do, in terms of their choice of behaviour pattern at any moment, and the time and effort they devote to performing it (e.g. Blackburn and Pfaus, 1988; Mason et al., 2001; Toates, 2001).

Motivation used to be thought of in terms of drives; thus a high hunger drive would lead to increased foraging and feeding. However, drive theories have been replaced by more complex models (see e.g. Barnard, 1983) based on motivational states (e.g. McFarland, 1993) that are determined by an array of internal and external factors. Thus, an animal's likelihood to feed is affected by internal factors (such as an energy deficit), but also the availability and palatability of different foods, and the presence of factors eliciting competing behaviours, such as the presence of predators. Motivated behaviour often has an appetitive preparatory phase (such as searching), which culminates in a more stereotyped, species-typical consummatory phase (such as eating, mating or fighting; e.g. McFarland, 1981). In some cases, motivation is controlled by negative feedback, e.g. if consummation is successful, this reduces motivation by altering the internal state and/or eliminating the relevant environmental cues. However, motivational mechanisms often involve more complex patterns of feedback; for example, the performance of appetitive behaviours per se may also serve to reduce motivation, or the performance of consummatory behaviour may actually increase motivation via positive feedback (e.g. Toates, 2001; see also Chapter 2, this volume).

The failure of such negative feedback loops is often thought to underlie stereotypies. For example, in captivity, some highly motivated consummatory behaviours (e.g. mating) may be impossible, regardless of the degree of appetitive behaviour (e.g. mate search) performed. In other cases, consummatory behaviour (e.g. feeding) may occur without the normal appetitive behaviours (e.g. grazing; Chapter 2, this volume) being possible. If such constraints leave animals in states of high motivation, this can result in frustration-related stress (e.g. Mason et al., 2001), and a number of behavioural phenomena (e.g. Dawkins, 1990) including 'intention movements' (e.g. the restless escape attempts of a migratory bird confined to a cage, Dawkins, 1988), 'redirected movements' (e.g. the sucking that calves direct to pen-mates and pen furnishings in the absence of a teat; e.g. Jensen, 2003), 'vacuum activities' (e.g. the 'mimed' dustbathing movements of hens kept on bare wire floors; Lindberg and Nicol, 1997), and/or 'displacement activities' (e.g. 'out of context' ground-pecking or preening by birds during conflict situations, e.g. Tinbergen, 1952). If sustained, these activities can then develop into stereotypies - a view supported by two types of study. The first is observational, tracking in detail the development of a stereotypy from one of these 'source behaviours' (cf. Mason, 1991b). Ödberg (1978), for instance, described the emergence of a paw-raising stereotypy from the repeated courtship movements of a male okapi prevented from reaching a female; and Duncan and Wood-Gush (1972), the development of pacing in food-frustrated hens repeatedly trying to escape a cage. The second is experimental, and involves identifying the specific internal states or external cues key in eliciting the stereotypic behaviours. These are often the same factors that elicit normal behaviour patterns (e.g. the role of hunger in pig oral stereotypies; Chapter 2, this volume; and the role of frustrated burrow requirements in stereotypic digging by gerbils; Chapter 4, this volume). Ödberg (1978) thus asserted that there is one common factor to all conditions [in which stereotypies develop]: frustration. In all situations some tendency is being thwarted, some goal cannot be reached, some homoeostasis is disrupted'. Since then, much research does indeed suggest this to be the case (Chapters 2-4 and Chapter 9, this volume). 
Box 1.2. A Quick Systems Sketch of Brain and Behaviour, and the Key Systems Implicated in Stereotypies

\section{J.P. Garner}

To understand stereotypies in captive animals, we need to understand why it is that repeated motor patterns or sequences are called up repetitively within a bout, so that they occur again and again despite no obvious goal or function; and why it is these bouts themselves are repeated from one occasion to the next. In some instances, we also need to understand why they are incredibly persistent, despite costs to the animal such as self-harm. In others, we also need to understand why they are so incredibly unvarying, such that animals perform exactly the same movements each time, for example, always placing their feet in the exact same spot while repeatedly pacing or climbing. Here, I give a brief overview of the brain systems involved, to help non-neuroscientists appreciate neuroscientists' accounts of these behaviours. How does the brain turn internal and external stimuli (e.g. motivationally relevant cues) into behavioural responses? The figure below gives a simple illustration of the three main steps involved when behaviour is generated.

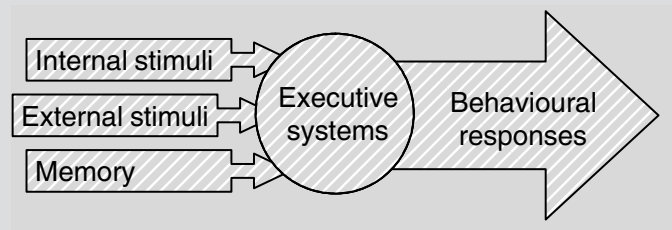

Information from the external world (via the senses) and about internal state (e.g. blood sugar levels, hormone levels) is processed and reduced to biologically meaningful information by separate systems. The cacophony of raw information arriving from the sensory organs is processed into biologically relevant representations by many dedicated perceptual systems operating in parallel, and the processing of information through these systems is called a 'stream'. For instance, visual information is first separated by the visual cortex into streams that identify form, movement, depth and colour. These visual streams are broadly integrated into an object recognition, or 'what' processing stream (located in the forebrain's temporal cortex) and a spatial and movement, or 'where' processing stream (in the parietal cortex).

All of this processing ultimately provides representations of the identity, position and movement of objects encoded in the 'cortical association areas'. The broader meaning of this information is integrated across the senses by the 'limbic system'. Associative memories are integrated and formed in interactions with the hippocampus, but the actual memories appear to be stored in the association areas that encoded the original representations. Internal physiological stimuli (cf. Box 1.1) are processed by the hypothalamus and relayed to other limbic areas. Further processing in the limbic system, especially the amygdala and orbitofrontal cortex, encodes emotional and value-related information (i.e. are the stimuli rewarding or aversive?) which together are termed 'affective' information.

The breadth of this information (i.e. perception, internal stimuli, memory, affect) is then processed by the brain's 'executive systems', to select and sequence both learned and instinctive behavioural responses for performance. These executive systems thus serve as a central hub for translating information into behaviour. Different executive systems have subtly different functions and are located in different areas of the brain. Probably the most important system for stereotypies is the 'contention scheduling system' involving the dorsal striatum of the basal ganglia, which selects individual movements (see Chapters 5 and 7 , this volume for more information). The 'supervisory attention system' located in the prefrontal cortex may also 


\section{Box 1.2. Continued}

play a role in some stereotypy-like behaviours, since it selects the overall 'plan' or behavioural context to be pursued (see Chapters 5 and 10, this volume for more information). Lastly, a system involving the nucleus accumbens (in the ventral striatum of the basal ganglia) may also be important since it plays a key role in determining the motivational importance accorded to a given behaviour (see Chapters 8 and 11, this volume, for more information).

The behaviours themselves are then produced by the motor systems. Motor 'programs' (the sequence of movements involved in a behaviour) are encoded in the premotor cortices, and are sequenced into individual movements by circuit loops running to the putamen (the posterior dorsal striatum) of the basal ganglia, these movements then being generated by the primary motor cortex. Thus, while sensory processing and motor functions are distinct, the executive systems are finely intertwined with the last stages of sensory and affective integration at the start of the executive processing 'stream' and the first stages of motor integration at the end of the executive 'stream'. The cerebellum modulates signals passing down the spinal cord from the motor cortex, aiding in fine feedback of movement and helping (together with executive and motor systems) coordinate the learning of highly automatic repetitive motor tasks (such as riding a bicycle). The cerebellum may thus play a role in changing some initially variable repeated movements into very predictable ones. For further details see Hubel (1988); Rolls (1994); Passingham (1995); Dias et al. (1996) and Brodal (2003).

\section{Box 1.3. The Coping Hypothesis of Stereotypic Behaviour}

\section{H. Würbel, R. Bergeron and S. Cabib}

Originally the term 'coping' pertained only to acutely stressful situations (e.g. electric shock; Dantzer, 1989; Wechsler, 1995), with 'coping response' referring to any behaviour apparently attenuating stressor-induced physiological responses (e.g. HPA activity, gastric ulcers). For instance, rats allowed to chew inedible objects during foot-shock showed less physiological stress than controls exposed to the same stressor but which were unable to perform these behaviours (Weiss, 1972; Tanaka et al., 1985; see also Berridge et al., 1999). More recently, the concept of coping has been extended to any fitness cost (e.g. Wiepkema, 1982; Wechsler, 1995) or perceived cost (i.e. negative subjective states; e.g. Lazarus and Folkman, 1984). 'Coping' then covers a broad range of responses, including both learnt behaviours (e.g. active avoidance) and unlearnt ones (e.g. hiding; fighting; displacement activities), which can either have very specific effects (e.g. reducing the HPA response to a specific stressor) or act as a 'general panacea' (i.e. attenuating negative subjective states in any adverse situation). Furthermore, some even use 'coping' to mean any behavioural attempt to control a situation, even if unsuccessful; thus Cabib (Chapter 8, this volume) presents a neurobiological conception of how unlearnt, species-typical 'coping' responses like escape attempts (which for caged animals, obviously fail) underlie stereotypies.

When used in research on stereotypic behaviour, however, 'coping' typically refers to a learnt response, which does have benefits (i.e. is at least partially successful) and may be rather specific in both cause and effects. Thus, the coping effects associated with performing a source behaviour are hypothesized to reinforce it, thereby leading to the repetitive performance typical of stereotypies. It has also been proposed that the coping effect of a stereotypy may not actually be bound to a specific situation, with the same stereotypy coming to act as a coping response in different situations, and serving as a panacea. So, what is the evidence for this idea? In the 1980s, some farm animal studies showed inverse relationships between 
Box 1.3. Continued

stereotypy performance and gastric ulceration or heart rate (Chapter 2, this volume). Other studies found that the opioid antagonist naloxone selectively disrupted stereotypy performance in sows (e.g. Cronin et al., 1985), and in analogy to the 'runner's high' (e.g. Pargman and Baker, 1980), a theory attributing euphoria during long distance running to the release of endogenous opioids, these authors suggested that animals perform stereotypies to selfnarcotize. Further support for coping came from laboratory rodent studies of amphetamine stereotypy (e.g. reviewed by Mason, 1991a) and human studies on the reported subjective consequences of stereotyping (e.g. reviewed by Mason and Latham, 2004). However, the 1990s saw much criticism of this idea. Evidence in favour of it was discounted as merely correlational, anecdotal or invoking 'coping' when other explanations were equally plausible (e.g. Rushen et al., 1990; Mason, 1991a,b; Rushen, 1993; Garner, 1999). Thus, for example, Dantzer (1991) concluded 'there is no evidence at all that performance of stereotypies results in increased opioid activity' (see Stoll, 1997 for a similar critique of the 'runner's high' in sports science). Experimental research on rodents also yielded findings at best ambiguous in their support of this hypothesis (Chapter 4, this volume). Furthermore, several other studies yielded results inconsistent with specific predictions of the coping hypothesis (e.g. Rushen et al., 1990;

Terlouw et al., 1991; Dantzer and Mittleman, 1993; McGreevy and Nicol, 1998).

Overall, there is no evidence that all stereotypies inevitably help animals cope or that a single mechanism (e.g. stress reduction) is always involved. Nevertheless, increasing evidence indicates that at least some stereotypies, in some species, do have some beneficial effects. Chapters 2 and 6 give some examples. Furthermore, the sheer number of correlational links between stereotypy performance and measures of improved welfare continue to intrigue, and to generate hypotheses as to how such effects might arise (Mason and Latham, 2004). However, whether any coping effects are truly causal in the development and continued performance of stereotypies, or merely beneficial side effects, remains unknown.

Box 1.4. Behavioural Pathology - Attempt at a Biologically Meaningful Definition

\section{H. WürBeL}

Pathology and disease are common words in everyday language, yet their precise biological meanings are elusive. This is mainly because 'pathology' - like 'abnormal' - is a normative rather than a biological term. According to Webster's Medical Dictionary, pathologies are 'the anatomic and physiological deviations from the normal that constitute disease or characterize a particular disease', with disease being 'an impairment of the normal state ... that interrupts or modifies the performance of the vital functions ...'. Thus, Novak and colleagues (Chapter 6 , this volume) describe stereotypies as 'pathological' when they take up excessive time or cause self-harm. However, what constitutes impaired performance often depends on circumstance, and on one's level of focus. Fever, for instance, might be classified as pathology because it has some negative side effects, yet fever is an adaptive, functional response of the organism to infection by pathogens. Thus, pathology might better be defined by its causes rather than its consequences, e.g. as 'a maladaptive phenotypic expression caused by dysfunction of one or several parts of the body'. This resembles Mills' (2003) definition of 'malfunctional': 'expressions of direct disruption ... (with) no functional value in any context', seizures being one such example. Such responses differ from expressions caused by mismatches between an animal's phenotype and its current environment (Bateson et al., 2004), or what Mills (2003) terms 'maladaptive' responses, defined for behaviours as 'attempts 


\section{Box 1.4. Continued}

to behave in an adaptive way in an environment to which complete adaptation is not possible'.

Behavioural pathologies (or malfunctional behaviours) will typically stem from dysfunction of the nervous system. Of course, we must note that dysfunction itself is also a normative term: no sharp boundary exists between normal, healthy function and pathological dysfunction, and dysfunction can only be defined with reference to the natural variation in phenotypic expression under natural (or near-to-natural) conditions, the boundary typically needing to be defined statistically. However, overall, stereotypies might be classified as adaptive, if they effectively serve a coping function (see Box 1.3); maladaptive, if they reflect normally adaptive responses occurring inappropriately, within an 'abnormal' environment; or pathological, if they are caused by dysfunction, e.g. within the nervous system.

\section{Acknowledgements}

We are indebted to Alistair Lawrence for his work on the first edition. Enormous thanks also go to all the contributors to this edition, who (despite occasional bouts of rage, despair and going completely AWOL) worked incredibly hard, and with intelligence, grace and humour.

\section{References}

Barnard, C.J. (1983) Animal Behaviour: Ecology and Evolution. Croom Helm, London.

Bateson, P., Barker, D., Clutton-Brock, T., Deb, D., D’Udine, B., Foley, R.A., Gluckman, P., Godfrey, K., Kirkwood, T., Lahr, M.M., McNamara, J., Metcalfe, N.B., Monaghan, P., Spencer, H.G. and Sultan, S.E. (2004) Developmental plasticity and human health. Nature 430, 419-421.

Berridge, C.W., Mitton, E., Clark, W. and Roth, R.H. (1999) Engagement in a nonescape (displacement) behavior elicits a selective and lateralized suppression of frontal cortical dopaminergic utilization in stress. Synapse 32, 187-197.

Blackburn, J.R. and Pfaus, J.G. (1988) Is motivation really modulation? A comment on Wise. Psychobiology 16, 303-304.

Brodal, P. (2003) The Central Nervous System: Structure and Function, 3rd edn. Oxford University Press, Oxford, UK.

Cronin, G.M., Wiepkema, P.R. and van Ree, J.M. (1985) Endogenous opioids are in- volved in abnormal stereotyped behaviours of tethered sows. Neuropeptides 6 , 527-530.

Dantzer, R. (1989) L'illusion Psychosomatique. Editions Odile Jacob, Paris.

Dantzer, R. (1991) Stress, stereotypy and welfare. Behavioural Processes 25, 95-102.

Dantzer, R. and Mittleman, G. (1993) Functional consequences of behavioural stereotypies. In: Lawrence, A.B. and Rushen, J. (eds) Stereotypic Animal Behaviour: Fundamentals and Applications to Welfare. CAB International, Wallingford, UK, pp. 147-172.

Dawkins, M.S. (1988) Behavioural deprivation: a central problem in animal welfare. Applied Animal Behaviour Science 20, 209-225.

Dawkins, M.S. (1990) From an animal's point of view: motivation, fitness, and animal welfare. Behavioural and Brain Sciences 13, 1-9.

Dias, R., Robbins, T.W. and Roberts, A.C. (1996) Dissociation in prefrontal cortex 
of affective and attentional shifts. Nature 380, 69-72.

Duncan, I.J.H. and Wood-Gush, D.G.M. (1972) Thwarting of feeding behaviour in the domestic fowl. Animal Behaviour 20, 444-451.

Garner, J.P. (1999) The aetiology of stereotypy in caged animals. Ph.D. thesis, University of Oxford, Oxford, UK.

Hubel, D.H. (1988) Eye, Brain, and Vision, Vol. 22. Scientific American Library, Distributed by W.H. Freeman, New York.

Jensen, M.B. (2003) The effects of feeding method, milk allowance and social factors on milk feeding behaviour and cross-sucking in group housed dairy calves. Applied Animal Behaviour Science 80, 191-206.

Ladewig, J., de Passillé, A.M., Rushen, J., Schouten, W., Terlouw, E.C.M. and von Borell, E. (1993) Stress and the correlates of stereotypic behaviour. In: Lawrence, A.B. and Rushen, J. (eds) Stereotypic Animal Behaviour: Fundamentals and Applications to Welfare. CAB International Wallingford, UK, pp. 97-118.

Lawrence, A.B. and Rushen, J. (1993) Introduction. In: Lawrence, A.B. and Rushen, J. (eds) Stereotypic Animal Behaviour: Fundamentals and Applications to Welfare. CAB International, Wallingford, UK, pp. 41-64.

Lazarus, R.S. and Folkman, S. (1984) Stress, Appraisal, and Coping. Springer, New York.

Lindberg, A.C. and Nicol, C.J. (1997) Dustbathing in modified battery cages: is sham dustbathing an adequate substitute? Applied Animal Behaviour Science 55, 113-128.

Mason, G.J. (1991a) Stereotypies: a critical review. Animal Behaviour 41, 1015-1037.

Mason, G.J. (1991b) Stereotypies and suffering. Behavioural Processes 25, 103-115.

Mason, G.J. (1993) Forms of stereotypic behaviour. In: Lawrence, A.B. and Rushen, J. (eds) Stereotypic Animal Behaviour: Fundamentals and Applications to Welfare. CAB International, Wallingford, UK, pp. 7-40.
Mason, G.J. and Latham, N.R. (2004) Can't stop, won't stop: is stereotypy a reliable animal welfare indicator? Animal Welfare 13 (Supplement), S57S69.

Mason, G., Cooper, J. and Clarebrough, C. (2001) The welfare of fur-farmed mink. Nature 410, 35-36.

Mason, G., Clubb, R., Latham, N. and Vickery, S. (2006) Why and how should we use environmental enrichment to tackle stereotypic behavior? Applied Animal Behaviour Science. Available online August 2nd 2006 doi: 10.106/japplanim. 2006.05.04/

McFarland, D. (1981) The Oxford Companion to Animal Behaviour. Oxford University Press, Oxford, UK.

McFarland, D. (1993) Animal Behaviour. Oxford University Press, Oxford, UK.

McGreevy, P. and Nicol, C.J. (1998) Physiological and behavioral consequences associated with short-term prevention of crib-biting in horses. Physiology and Behavior 65, 15-23.

Mills, D.S. (2003) Medical paradigms for the study of problem behaviour: a critical review. Applied Animal Behaviour Science 81, 265-277.

Moberg, G.P. and Mench, J.A. (2000) The Biology of Animal Stress: Principles and Implications for Animal Welfare. CABI Publishing, Wallingford, UK.

Ödberg, F.O. (1978) Abnormal behaviours: stereotypies. In: First World Congress on Ethology Applied to Zootechnics, October 23-27, Madrid, Industrias Grafices Espana, pp. 475-480.

Ödberg, F.O. (1993) Future research directions. In: Lawrence, A.B. and Rushen, J. (eds) Stereotypic Animal Behaviour: Fundamentals and Applications to Welfare. CAB International, Wallingford, UK, pp. 173-192.

Pargman, D. and Baker, M. (1980) Running high: enkephalin indicted. Journal of Drug Issues 10, 341-349.

Passingham, R. (1995) The Frontal Lobes and Voluntary Action. Oxford University Press, Oxford, UK. 
Rolls, E.T. (1994) Neurophysiology and cognitive functions of the striatum. Revue Neurologique 150, 648-660.

Rushen, J. (1993) The coping hypothesis of stereotypic behaviour. Animal Behaviour 48, 91-96.

Rushen, J., de Passillé, A.M.B. and Schouten, W. (1990) Stereotypic behaviour, endogenous opioids, and post-feeding hypoalgesia in pigs. Physiology and Behavior 48, 91-96.

Stoll, O. (1997) Endorphine, Laufsucht und Runner's High. Aufstieg und Niedergang eines Mythos. Leipziger Sportwissenschaftliche Beiträge 28, 102-121.

Tanaka, T., Yoshida, M., Yokoo, H., Tomita, M. and Tanaka, M. (1985) Expression of aggression attenuates both stressinduced gastric ulcer formation and increases in noradrenaline release in the rat amygdala assessed by intracerebral microdialysis. Pharmacology and Biochemistry of Behaviour 59, 27-31.

Terlouw, E.M.C., Lawrence, A.B., Ladewig, J., de Passillé, A.M.B., Rushen, J. and
Schouten, W.G.P. (1991) Relationship between plasma cortisol and stereotypic activities in pigs. Behavioural Processes 25, 133-153.

Tinbergen, N. (1952) 'Derived' activities: their causation, biological significance, origin and emancipation during evolution. Quarterly Review of Biology 27, 1-32.

Toates, F. (2001) Biological Psychology. Pearson Education Limited, Harlow, UK. Wechsler, B. (1995) Coping and coping strategies - a behavioural review. Applied Animal Behaviour Science 43, 123-134.

Wiepkema, P.R. (1982) On the identity and significance of disturbed behaviour in vertebrates. In: Bessei, W. (ed.) Disturbed Behaviour in Farm Animals. Ulmer, Stuttgart, pp. 1-17.

Weiss, J.M. (1972) Influence of psychological variables on stress-induced pathology. In: Porter, R. and Knight, J. (eds) Physiology, Emotion and Psychosomatic Illness. CIBA Foundation Symposium. Elsevier, Amsterdam. 